\title{
PENGARUH MIRROR THERAPY TERHADAP PEMENUHAN ACTIVITY DAILY LIVING PADA PASIEN PASCA STROKE (DI POLI SARAF RSUD NGANJUK)
}

\author{
Oktaffrastya W. Septafani ${ }^{1}$, Shella Mangga Trusilawati ${ }^{2}$, Sujatmiko $^{3}$ \\ ${ }^{123}$ STIKes Satria Bhakti Nganjuk \\ Email : oktafssbn@gmail.com
}

\begin{abstract}
Introduction : Stroke cause some impact that is disability that can affect or disturb someone in doing Activity Daily Living (ADL). For that, patients need exercise in order to do simple things. The purpose of this study is determine the effect of Mirror Therapy on the fulfillment of Activity Daily Living in patients post-stroke (in Nerve Polis RSUD Nganjuk).Methode : the desaign of this study used Preexperimental with one-group pre-post test design approach. It conducted on March $26^{\text {th }}-$ May $6^{\text {th }} 2018$ , The population evenly in one month as many as 110 people. The sampling technique was Purposive Sampling, Samples were 11 post-stroke patients according to inclusion criteria. The independent variable was Mirror Terapy and the dependent variable was the fulfillment of Activity Daily Living. Data collection used Barthel index observation sheets. Statistical test using Wilcoxon with significance $\alpha=0.05$.Result : The result of this study of 11 respondents almost half that was 5 respondent fulfillment of Activity Daily Living before being given mirror therapy had intermediate dependency interpretation. From 11 respondents most of which are 6 respondents fulfillment of Activity Daily Living after given mirror therapy have intermediate dependency interpretation. Before, being given mirror therapy one respondents had a total dependency interpretation of increasing heavy dependence, and two respondents with intermediate dependence increased to be independent after being given mirror therapy, so Ha was accepted with $\rho$ value $=0,020 \leq \alpha=0,05$. Conclusions : There was the effect of mirror therapy with fulfillment Activity Daily Living in post-stroke patients.Mirror therapy can be used as additional therapy for post-stroke patients to improve functional motor abilities.
\end{abstract}

Keyword : Post-stroke, Mirror Therapy, Activity Daily Living

\section{PENDAHULUAN}

Stroke adalah penyebab utama kecacatan jangka panjang yang serius pada orang dewasa.Pasca stroke, fungsi motorik ekstremitas seringkali terganggu menyebabkan pembatasan pada mobilitas fungsional (Sengkey, 2014).Pasien pasca stroke tidak dapat menjalankan aktivitas sehari-hari secara optimal sehingga mengakibatkan ketergantungan dalam memenuhi kebutuhan sehari-hari (Reni, 2014). Sama ketika masih sehat, pasien pasca stroke juga perlu dicukupi kebutuhan dasarnya (Lingga, 2013).Upaya untuk memulihkan anggota gerak adalah dengan melakukan rehabilitasi (Karunia, 2016).Meskipun, perbaikan dilakukan dengan rehabilitasi, pemulihan pasca stroke tetap lebih lambat dan beragam (Crosby, $\mathrm{dkk}$, 2016). Oleh karena itu, diperlukan suatu teknik yang memungkinkan pemulihan otak yang lebih efisien dan mengeksplorasi mekanisme potensial yang terlibat dalam stroke. Mirror therapy merupakan salah satu terapi terbaru yang telah menarik minat karena sederhana dan 
rendah biaya (Guo, dkk, 2016). Menurut penilitian yang dilakukan oleh Yavuzer, dkk (2008), bahwa pada kelompok pasien stroke subakut, fungsi tangan membaik setelah diberikan mirror therapy di samping program rehabilitasi konvensional dibandingkan dengan kontrol pengobatan dan pada follow up setelah 6 bulan, serta mirror therapi tidak menyebabkan spatisitas.

Sebanyak $5 \%$ orang Indonesia berusia di atas 65 tahun pernah mengalami setidaknya satu kali serangan stroke (Suharti, 2016). Berdasarkan hasil data Rekam Medik RSUD Nganjuk tahun 2017 bulan Januari - September rata-rata kunjungan per bulan pasien pasca stroke sebanyak 807 kasus.

Menurut Hadiwynoto (2005), faktor yang memepengaruhi penurunan activity daily living salah satunya adalah kondisi fisik misalnya penyakit menahun. Stroke menimbulkan kecacatan fisik berupa penurunan kemampuan motorik yang mengakibatkan penurunan kemampuan aktivitas (Fadlulloh, 2014). Keterbatasan fisik dan mental mengharuskan pasien pasca stroke menjadi bergantung pada orang lain, setidaknya untuk sementara waktu hingga kondisi fisik dan mentalnya membaik (Lingga, 2013).Sebuah survei yang dilakukan oleh National Stroke Institute di Amerika menjelaskan bahwa empat tahun pasca stroke masih menimbulkan dampak yang sulit ditutupi oleh pasien pasca stroke. Dari waktu ke waktu, stroke menimbulkan dampak yang berbeda-beda bagi penderitanya. Semakin lama proses pemulihan berlangsung, semakin parah dampak yang ditimbulkannya.

Di samping upaya medikasi melalui obat, latihan fisik secara rutin merupakan upaya terapi rehabilitasi yang umumnya dianjurkan untuk dilakukan pasca stroke. Rehabilitasi pasca stroke merupakan suatu upaya rehabilitasi stroke terpadu yang melibatkan berbagai disiplin ilmu dan merupakan kumpulan program. Perlu adanya alternatif bentuk rehabilitasi yang memungkinkan penderita stroke untuk menjalani latihan terapi fisik (Sengkey \& Pandeiroth, 2014). Selain terapi rehabilitasi yang sering dilakukan pada pasien pasca stroke, terdapat alternatif terapi lainnya yang dapat diterapkan pada pasien untuk meningkatkan status fungsional pada sensorik motorik, yaitu terapi latihan dengan menggunakan media cermin (mirror therapy). Pada tahun 1999, Altschuler, dkk memperkenalkan penggunaan mirror therapy untuk rehabilitasi stroke (Guo, dkk, 2016). Terapi ini digunakan untuk memperbaiki fungsi motorik pasca stroke. Sehingga mirror therapy dapat dikombinasi dengan program rehabilitasi konvensional dalam meningkatkan pemulihan motorik 
ekstremitas dan fungsional pada pasien pasca stroke (Suharti, 2016).

Mirror Therapy adalah intervensi terapeutik yang relatif baru yang berfokus pada pergerakan anggota badan yang tidak mengalami gangguan. Terapi ini pertama kali diperkenalkan oleh Ramachandra, dkk pada tahun 1996 untuk mengobati rasa sakit pada tungkai setelah amputasi.Sengkey \& Pandeiroth (2014), melakukan penelitian perbandingan antara terapi latihan dan terapi latihan menggunakan mirror therapy pada pemulihan fungsi motorik anggota tubuh bawah pada pasien pasca stroke, hasilnya bahwa latihan menggunakan mirror therapy dapat memperbaiki fungsi anggota tubuh bawah secara signifikan pada pasien pasca stroke. Sebagai tambahan, mirror therapy merupakan terapi sederhana, tidak mahal, dan terapi dasar untuk pasien. Tujuan dari penelitian ini adalah untuk mengetahui "pengaruh mirror therapy terhadap pemenuhan activity daily living pada pasien pasca stroke (di Poli Saraf RSUD Nganjuk)".

\section{METODE PENELITIAN}

Penelitian ini menggunakan rancangan penelitian Pra-experimental, dengan pendekatan one-group pre-post test design yaitu rancangan mengungkapkan hubungan sebab akibat dengan cara melibatkan satu kelompok subjek (Nursalam, 2016). Penelitian ini dilakukan dengan cara kelompok subjek diobservasi sebelum dilakukan intervensi, kemudian diobservasi lagi setelah intervensi (Nursalam, 2016). Penelitian dilaksanakan pada tanggal 26 Maret - 6 Mei 2016.

Populasi dalam penelitian ini adalah adalah semua pasien pasca stroke di Poli Saraf RSUD Nganjuk, Kabupaten Nganjuk rata-rata dalam 1 bulan sebanyak 110 orang. Teknik sampling yang digunakan dalam penelitian ini adalah purposive sampling, dengan jumlah sampel sebanyak 11 orang sesuai dengan kriteria inklusi. Dengan kriteria inklusi sebagai berikut : 1). Pasien pasca stroke yang berusia 30 - 60 tahun, 2). Pasien yang bersedia menjadi responden, 3). Pasien yang mengalami hemiplegia / hemiparesis kanan atau kiri 4). Pasien yang tidak mengalami gangguan kognitif dan visual. Sedangkan kriteria eksklusi sebagai berikut : 1). Pasien pasca stroke yang disertai gangguan penglihatan dan pendengaran, 2). Pasien yang mengalami kontraktur.Variabelindependendalampenel itianiniadalahmirror therapy dengan menggunakan SOP (Standart Operating Prosedur) sebagai berikut : 1). Cermin diletakkan ditengah memotong tubuh, 2). Tangan yang tidak terganggu didepan cermin, 3). Pasien diintruksikan melihat bayangan cermin seolah sebagai lengan yang terganggu dengan konsentrasi tinggi dan menggerakkannya, 4). Pada waktu yang bersamaan pasien diminta menggerakkan 
kedua tangan dan cermin ukuran $60 \times 50 \mathrm{~cm}$ dengan model L sebagai alat dalam latihan dan Variabel dependen dalam penelitian ini adalah pemenuhan Activity Daily Living dengan lembar observasi indeks Barthel.

Indeks Barthel terdiri dari 10 item,yaitu :pindah kursi/tempat tidur, berjalan/dengan kursi roda, naik tangga, toileting, kontrol bowel, kontrol urin, mandi, berpakaian, kebersihan diri, makan, dengan skor total berkisar dari 0 (ketergantung total) - 100 (mandiri). Interpretasi Activity Daily Living responden berdasarkan jumlah skor menurut Shah, dkk (1999). Jumlah total skor sebagai berikut skor 0-20 yaitu ketergantungan total, skor 21-60 yaitu ketergantungan berat, 61-90 yaitu ketergantungan sedang, skor 91-99 yaitu ketergantungan ringan, skor 100 yaitu mandiri.

Data yang telah dikategorikan kemudian dianalisis dengan uji statistik terhadap pemenuhan Activity Daily Living menggunakan uji Wilcoxon dengan $\alpha=$ 0.05 .

\section{HASIL PENELITIAN}

Tabel 1. Distribusi Frekuensi Activity Daily Living Pada Pasien Pasca Stroke Sebelum Diberikan MirrorTherapy di Poli Saraf RSUD Nganjuk pada tanggal 26 Maret - 6 Mei 2018

\begin{tabular}{cccc}
\hline No. & Intepretasi Activity Daily Living & $\boldsymbol{f}$ & $\mathbf{\%}$ \\
\hline 1. & Ketergantungan Total & 1 & 9,09 \\
\hline 2. & Ketergantungan Berat & 3 & 27,17 \\
\hline 3. & Ketergantungan Sedang & 5 & 45,46 \\
\hline 4. & Ketergantungan Ringan & 2 & 18,18 \\
\hline 5. & Mandiri & 0 & 0 \\
\hline & Jumlah & 11 & 100 \\
\hline
\end{tabular}

Berdasarkan tabel 1 dapat diketahui bahwa 11 responden sebelum diberikan mirrortherapy di Poli Saraf RSUD Nganjuk, Hampir setengahnya yaitu 5 Responden (45,46\%) memiliki intepretasi ActivityDailyLiving ketergantungan sedang.

Tabel 2. Distribusi Frekuensi Activity Daily Living pada Pasien Pasca Stroke Sesudah Diberikan Mirror Therapy di Poli Saraf RSUD Nganjuk pada tanggal 26 Maret - 6 Mei 2018.

\begin{tabular}{cccc}
\hline No. & Intepretasi Activity Daily Living & $F$ & $\%$ \\
\hline \hline 1. & Ketergantungan Total & 0 & 0 \\
\hline 2. & Ketergantungan Berat & 2 & 18,18 \\
\hline 3. & Ketergantungan Sedang & 6 & 54,55 \\
\hline
\end{tabular}




\begin{tabular}{cccc}
\hline 4. & Ketergantungan Ringan & 0 & 0 \\
\hline 5. & Mandiri & 3 & 27,27 \\
\hline & Jumlah & 11 & 100 \\
\hline
\end{tabular}

Berdasarkan tabel 2 dapat diketahui bahwa dari 11 responden sesudah diberikan mirrortherapy di Poli Saraf RSUD Nganjuk, sebagian besar 6 responden (54,55\%) memiliki intepretasi ActivityDailyLiving ketergantungan sedang

Tabel 3. Pemenuhan Activity Daily Living pada pasien pasca stroke sebelum dan sesudah diberikan Mirror Therapy di Poli Saraf RSUD Nganjuk pada tanggal 26 Maret - 6 Mei 2018.

\begin{tabular}{ccccccc}
\hline No. & $\begin{array}{c}\text { Intepretasi Activity Daily } \\
\text { Living sebelum Mirror } \\
\text { Therapy }\end{array}$ & $f$ & $\%$ & $\begin{array}{c}\text { Intepretasi Activity Daily } \\
\text { Living sesudah Mirror } \\
\text { Therapy }\end{array}$ & $f$ & $\%$ \\
\hline 1. & Ketergantungan total & 1 & 9,09 & Ketergantungan total & 0 & 0 \\
\hline 2. & Ketergantungan berat & 3 & 27,27 & Ketergantungan berat & 2 & 18,18 \\
\hline 3. & Ketergantungan sedang & 5 & 45,46 & Ketergantungan sedang & 6 & 54,55 \\
\hline 4. & Ketergantungan ringan & 2 & 18,18 & Ketergantungan ringan & 0 & 0 \\
\hline 5. & Mandiri & 0 & 0 & Mandiri & 3 & 27,27 \\
\hline Mean & $\mathbf{2 , 7 2}$ & & & $\mathbf{3 , 3 6}$ & $\mathbf{1 1}$ & $\mathbf{1 0 0}$ \\
\hline
\end{tabular}

\section{Uji Wilcoxon didapatkan $\rho$ value $0,020 \leq \alpha=0,05$}

Berdasarkan tabel 3 Uji wilcoxon pada pemenuhan Activity Daily Living didapatkan svalue $=0,020 \leq \alpha=0,05)$ maka $\mathrm{H}_{1}$ diterima $\mathrm{H}_{0}$ ditolak, sehingga ada Pengaruh mirror therapy terhadap pemenuhan Activity Daily Living pada pasien pasca stroke di Poli Saraf RSUD Nganjuk.

\section{PEMBAHASAN}

Berdasarkan hasil penelitian dapat diketahui bahwa dari 11 responden sebelum diberikan mirror therapy hampir setengahnya yaitu 5 responden $(45,46 \%)$ memiliki interpretasi Activity Daily Living ketergantungan sedang dan sesudah diberikan mirror therapy sebagian besar yaitu 6 responden $(54,55 \%)$ memiliki interpretasi Activity Daily Living ketergantungan sedang. Dari 11 responden yaitu 1 responden (9,09\%) sebelum diberikan mirror therapy memiliki intepretasi ketergantungan total meningkat menjadi ketergantungan berat, dan 2 responden $(18,18 \%)$ sebelum diberikan mirror therapy dengan ketergantungan 
ringan meningkat menjadi mandiri sesudah diberikan mirror therapy.

Hasil uji Wilcoxon didapatkan pvalue $=0,020 \leq \alpha=0,05)$ maka $\mathrm{H}_{1}$ diterima $\mathrm{H}_{0}$ ditolak, sehingga ada Pengaruh mirror therapy terhadap pemenuhan Activity Daily Living pada pasien pasca stroke di Poli Saraf RSUD Nganjuk.

Keadaan pasien pascastroke dalam pejalanannya sangat beragam, bisa pulih sempurna, bisa sembuh dengan cacat ringan, sedang, dan cacat berat khususnya pada kelompok umur diatas 45 tahun (Junaidi, 2011). Keterbatasan fisik dan mental mengharuskan pasien pasca stroke menjadi bergantung pada orang lain, setidaknya untuk sementara waktu hingga kondisi fisik dan mentalnya membaik. Menghadapi kondisi seperti ini, peran keluarga dan orang-orang terdekat sangat penting agar pasien dapat mencukupi kebutuhan hidupnya dengan baik (Lingga, 2013). Berdasarkan analisis risiko, dukungan keluarga berisiko menyebabkan kemandirian aktivitas kehidupan seharihari atau ADL pascastroke (Karunia, 2015).

Tingginya kemandirian diakibatkan karena responden sering melakukan ADL. Disamping itu, responden juga rajin dan patuh melaksanakan terapi, baik dirumah maupun di rehabiliasi medik (Karunia, 2015).Berlatih dan berlatih. Demikian cara yang paling efektif untuk memulihkan kelumpuhan. Rehabilitasi adalah suatu program yang disusun untuk memberi kemampuan kepada penderita yang mengalami disabilitas fisik dan atau penyakit kronis, agar mereka dapat hidup atau bekerja sepenuhnya sesuai dengan kapasitasnya (Harsono, 1996).

Selain terapi yang sering dilakukan pada pasien pasca stroke, terdapat terapi tambahan lainnya yang dapat diterapkan pada pasien pasca stroke untuk meningkatkan status fungsional pada sensorik motorik, yaitu terapi latihan menggunakan media cermin (mirror therapy).

Mirror therapy adalah bentuk rehabilitasi atau latihan yang mengandalkan dan melatih pembayangan atau imajinasi motorik pasien, dimana cermin akan memberikan stimulasi visual kepada otak melalui observasi dari pergerakan tubuh yang akan ditiru seperti cermin oleh bagian tubuh yang mengalami gangguan (Agusman \& Kusgiarti, 2017). Menurut Yavuzer, dkk (2008), bahwa ilusi visual dapat membuat pasien merasa seolah-olah kedua tangan dapat bergerak simetris secara stimulan aktif baik di otak kiri dan kanan dan meningkatkan rangsangan pada bagian yang terganggu. Terapi ini efektif dalam memperbaiki fungsi motorik (baik ekstremitas atas maupun bawah) dan 
aktivitas kehidupan sehari-hari (Sengkey \& Pandeiroth, 2014).

Altschuler, dkk (1999), melaporkan bahwa efek mirrortherapyterhadap kemampuan gerakan pasien pasca stroke, meliputi lingkup gerak sendi, kecepatan, dan ketepatan gerakan lebih baik pada kelompok mirror dibanding terapi lain. Tripathi (2016) dalam penelitiannya menunjukkan bahwa mirror therapy sebagai terapi tambahan lebih bermanfaat dalam pemulihan motorik dan fungsi yang berhubungan dengan tangan. Penelitian ini sejalan dengan Young Park, dkk (2015), dalam jurnalnya yang berjudul "The effect of mirror therapy on upper-extremity function and activities of daily living in stroke patients". Menunjukkan adanya peningkatan yang signifikan skor FIM self care dalam kemampuan untuk melakukan aktivitas sehari-hari pada pasien pasca stroke.

Mirror therapy termasuk terapi yang sederhana dan mudah dilakukan dengan membutuhkan konsentrasi yang tinggi. Sehingga pasien pasca stroke dianjurkan untuk latihan menggunakan mirror therapy sebagai terapi tambahan untuk memulihkan kemampuan motoriknya dan aktivitas sehari-hari.

\section{KESIMPULAN}

Pemenuhan Activity Daily Living sebelum diberikan mirror therapy dari 11 responden hampir setengahnya yaitu 5 responden $(45,46 \%)$ memiliki intepretasi ketergantungan sedang dan sesudah diberikan mirror therapy sebagian besar yaitu 6 responden $(54,55 \%)$ memiliki intepretasi ketergantungan sedang.Dari 11 responden yaitu 1 responden $(9,09 \%)$ sebelum diberikan mirror therapy memiliki intepretasi ketergantungan total meningkat menjadi ketergantungan berat, dan 2 responden $(18,18 \%)$ sebelum diberikan mirror therapy dengan ketergantungan ringan meningkat menjadi mandiri sesudah diberikan mirror therapy. Ada pengaruh mirror therapy terhadap pemenuhan Activity Daily Living pada pasien pasca stroke di Poli Saraf RSUD Nganjuk. Hal ini dibuktikan dengan nilai signifikan $\rho$ value $=$ $0,020 \leq \alpha=0,05$.

Bagi penelitian selanjutnya dapat menambah jumlah responden dan frekuensi latihan agar hasil yang didapatkan lebih baik dan maksimal, serta dapat dengan menggunakan dua kelompok yaitu kelompok kontrol dan perlakuan.

\section{DAFTAR PUSTAKA}

Agusman M, F. \& Kusgiarti, E. 2017. Pengaruh Mirror Therapy Terhadap Kekuatan Otot Pasien Stroke Non Hemoragik Di RSUD Kota Semarang. http://stikesyahoedsmg.ac.id/ojs/index .php/sjkp/article/view/95,

Altschuler EL, Wisdom SB, Stone L, Foster C, Galasko D, Llewellyn D. 1999. Rehabilitation of hemiparesis after 
stroke with a mirror. Lancet;353(9169):2035

Crosby, L.D.,Marrocco, S., Brown, J., Patterson, K.K. 2016. A Novel Bilateral Lower Extremity Mirror Therapy Intervention for Individuals With Stroke.http://dx.doi.org/10.1016/j.heliy on.20 16.e00208.

Guo, F., Xu, Q., Salem, H.M.A, Yao, Y., Lou, J., Huang, X. 2016. The Neuronal Correlates of Mirror Therapy : A Functional Magnetic Resonance Imaging Study on MirrorInduced Visual Illusons of Ankle Movements. Brain Research. https://www.sciencedirect.com/science /article/pii /S0006899316301184,

Hidayat. 2009. Metode Penelitian Keperawatan dan Teknik Analisa Data. Jakarta: Salemba Medika.

Irma \& Santi. 2015. Hubungan Antara Karakteristik Pasien Stroke Dan Dukungan Keluaraga Dengan Kepatuhan Menjalani Rehabilitasi. https://ejournal.unair.ac.id/JBE/article/ view/13 10, (diakses pada tanggal 7 Mei 2018).

Johanna. 2013. Identifikasi Kebutuhan Akan Sistem Rehabilitasi Berbasis Teknologi Terjangkau Untuk Penderita Stroke Di Indonesia, Lembaga Penelitian dan Pengabdian kepada Masyarakat Universitas Katolik Parahyangan. Junaidi, I. 2011. Stroke : Waspadai Ancamannya (I ed.). Yogyakarta: ANDI.

Karunia, E. 2016. Hubungan Dukungan Keluarga Dengan Kemandirian Activity of Daily Living Pascastroke. https://ejournal.unair.ac.id/index.php/J BE/article/view/2147, (diakses pada tanggal 7 Mei 2018 ).

Lingga, L. 2013. ALL ABOUT STROKE : Hidup Sebelum dan Pasca Stroke. Jakarta: PT Elex Media Komputindo.

Nursalam. 2016. Metodologi Penelitian Ilmu Keperawatan : Pendekatan Praktis. Jakarta: Salemba Medika.
Pratiwi, A. 2017. Prosedur Mirror Therapy Pada Pasien Stroke, Seminar Nasinal Keperawatan.http://www.conference.u nsri.ac.id/index.php/SNK/article/view/ $\underline{765,}$

Purwanti \& Maliya. 2008. Rehabilitasi Klien Pasca Stroke.

Riwidikdo, H. 2012. Statistik Kesehatan. Yogjakarta : Nuha Medika.

Rossiter, H.E., Borelli, M.R., Borchert, R.J., Bradbury, D., Ward, N. 2014. Cortical Mechanisms Of Mirror Therapy After Stroke.http://journals.sagepub.com/doi/ abs/10.1177/1545968314554622,

Sengkey \& Pandeiroth. 2014. Mirror Therapy in Stroke Rehabilitation, Volume 6, Nomor 2, hlm. 84-90. https://ejournal.unsrat.ac.id/index.php/ biomedik/article/view/5548.

Setiadi. 2013. Konsep dan Praktik Penulisan Riset Keperawatan, Edisi 2. Yogyakarta : Graha Ilmu.

Suharti. 2016. Efektivitas Penggunaan Cermin Terhadap Kemampuan Bicara Pada Pasien Stroke Dengan Afasia Motorik Di SMC RS Telogorejo.

Widyawati, S. 2016. Hubungan Motivasi Dengan Tingkat Kemandirian Dalam Pemenuhan Activity Daily Livings pada Pasien Pasca Stroke (di Poli Saraf RSUD Nganjuk) No. 123, hal. 2640.Skripsi. Nganjuk : STIKes Satria Bhakti Nganjuk.

Widyanto, F. C., \& Triwibowo, C. 2013. TREND DISEASE "Trend Penyakit Saat Ini". Jakarta: TIM.

Yavuzer, G., Selles, R., Sezer, N., Sutbeyaz, S., Bussmann, J.B. 2008. Mirror Therapy improves hand fuction in Subacute Stroke : a Randomized Controlled Trial. Arch Phys Med Rehabil : $89:$ 393-8.

Young Park, Jin, Chang, Moonyoung, Mi Kim, Kyeong, Jung Kim, Hee. 2015. The Effect of Mirror Therapy on Upper-Extremity Function And Activities of Daily Living in Stroke Patients, vol. 27, hal. 1681-1683. https://www.jstage.jst.go.jp/article/jpts 
/27/6/27 jpts-2014-

648/ article/char/ja/. (Diakses pada tanggal 13 Januari 2017). 